Proceedings of the 2011 Winter Simulation Conference

S. Jain, R.R. Creasey, J. Himmelspach, K.P. White, and M. Fu, eds.

\title{
ENERGY BALANCE FRAMEWORK FOR NET ZERO ENERGY BUILDINGS
}

\author{
Ravi S. Srinivasan \\ M.E. Rinker, Sr. School of Bldg. Construction \\ College of Design, Construction and Planning \\ University of Florida \\ Gainesville, FL 32611, USA \\ Daniel P. Campbell \\ US EPA Office of Research and Development \\ National Health and Env. Effects Research Lab \\ Atlantic Ecology Division \\ Narragansett, RI 02882, USA
}

\author{
William W. Braham \\ Department of Architecture \\ School of Design \\ University of Pennsylvania \\ Philadelphia, PA 19104, USA
}

\author{
Charlie D. Curcija \\ Windows and Daylighting Group \\ Building Technologies Department \\ Lawrence Berkeley National Laboratory \\ Berkeley, CA 94720, USA
}

\begin{abstract}
Approaching a Net Zero Energy (NZE) building goal based on current definitions is flawed for two principal reasons - they only deal with energy quantities required for operations, and they do not establish a threshold, which ensures that buildings are optimized for reduced consumption before renewable systems are integrated to obtain an energy balance. This paper develops a method to maximize renewable resource use through emergy (spelled with an "m") analysis. A "Renewable Emergy Balance" (REB) in environmental building design is proposed as a tool to maximize renewable resource use through disinvestment of all non-renewable resources that may be substituted with renewable resources. REB buildings attain a high standing by optimizing building construction over their entire life-span from formation-extractionmanufacturing to maintenance and operation, and material reuse at the end of building life-time.
\end{abstract}

\section{INTRODUCTION}

Net Zero Energy definitions are still in the early phase of development as new knowledge is drawn upon to revise and classify buildings. NZE can be defined based on boundaries determined by energy-flow and renewable supply options. While energy flow- based NZE definitions are determined by means of segregating the boundaries of energy consumption and generation (i.e., at the site or source levels), and their quantification (i.e., energy quantity or energy costs), the renewable supply options- based NZE definitions are established by way of demand-side location of on-site renewable capacities. These improvements can be derived from the buildings' energy consumption and/or generation (Toricellini et al. 2006) can be categorized as Net Zero Site Energy, Net Zero Source Energy, Net Zero Energy Costs and Net Zero Energy Emissions. On the other hand, demand-side renewable supply options based NZE definitions (Crawley et al. 2009) such as "on-site supply options," and "off-site supply options" offer definitions based on the location of the site of the renewable contributions.

The notion that raw materials for building construction are plentiful and can be extracted "at will" from Earth's geobiosphere, and that these materials do not undergo any degradation or related deterioration in energy performance while in use is alarming and entirely inaccurate. It must be acknowledged that only a finite mass of material resource exists irrespective of the multitude of transformations needed to make a product, and that entropic degradation of such products is inevitable. For these reasons, a particu- 


\section{Srinivasan, Braham, Campbell, and Curcija}

lar building, like an organism or an ecosystem must seek self-sustenance to prevail in competition with other building designs in a time with limited availability of energy and materials. To this extent, NZE buildings achieve a net annual operating energy balance. However, approaching a NZE building goal based on current definitions is flawed for the following reasons:

(a) NZE definitions only deal with operating energy quantities and related emissions.

NZE definitions deal with operating energy quantities and related emissions and do not include all other energy inflows required for the particular building to exist, e.g., the energy required for building manufacturing, maintenance, etc., In current NZE practice, this vast quantity of energy is unaccounted for and ignored for simplification purposes and perhaps also because up to this time there has not been a way to efficiently and accurately quantify these requirements in a uniform manner. In addition, current definitions and calculations for NZE do not include the energy flows from the sun, wind, rain, geological cycles and so-forth from the beginning and by including them using the emergy methodology, we demonstrate how a complete energy and material balance for buildings can be quantified.

(b) NZE definitions do not establish an "energy threshold" which ensures that buildings are optimized for reduced consumption of resources before renewable systems are integrated to obtain an energy balance.

Current NZE definitions are at a level that is particularly generic and does not provide information on the desired "energy threshold" to optimize building energy consumption prior to renewable system integration. For example, a building can attain NZE status by way of surplus renewable energy generation without optimizing its building energy consumption as can be noted in several of the current NZE projects. Such an approach defeats the goal of NZE and may not fulfill the larger objective of energy efficiency.

More importantly, for a building design strategy that aims to contribute to the larger goal of global sustainability, it must be acknowledged that a building relies on inputs from and outputs to the geobiosphere for its very existence. Current definitions and calculations of net energy do not include the energy flows from the sun, wind, rain, geological cycles, and so-forth from the beginning. Therefore, using NZE definitions without fully encompassing all related system forces and adequate scientific substantiation is misleading and, in the long run, it may be detrimental to building science, specifically when promoted by a premier organization such as the US Department of Energy.

\subsection{Environmental Accounting and Buildings}

Although buildings evolve through a rigorous decision-making process in terms of design and engineering, it is crucial to ask if an environmentally conscious approach went into the selection of building components, both for the whole building and for its sub-systems. While energy accounting can be expanded to include energy flows of the geobiosphere that shape an environmental building design and thereby mimic an ecological accounting model, it lacks two significant components in its bookkeeping. They are (a) lack of an internal optimizing principle and (b) the ability to quantify the environment's role in absorbing and processing pollution (Herendeen 2004). The internal optimizing principle is a distinctive characteristic of a reductionist tool. However, energy accounting may be used to implement external principles such as minimizing fossil fuel use, etc. From the perspective of the integration of renewable resource use into energy accounting, they are mere external constraints. Additionally, questions related to system boundaries in energy accounting and the merging of several types of energy are noteworthy, especially in expanding the energy accounting principles to the geobiosphere level (Hau 2005).

On the other hand, an ecological accounting model may offer environmental decision-making solutions through elaborate bookkeeping. Such a model is supported through a variety of inputs and outputs. Inputs may include building components' embodied energy and may even extend to the material forma- 


\section{Srinivasan, Braham, Campbell, and Curcija}

tion cycle to its lifetime, reiterating the notion that one may not withdraw non-renewable resources "at will" as there is only a finite quantity of those materials on this planet for use during its lifetime. Outputs may include the work products of that particular building. Some of the methods widely used are Life Cycle Assessment (LCA), emergy analysis, etc. LCA is a tool that primarily focuses on the impact of emissions and resource consumption (Guinee et al. 1993a; 1993b). However, Burgess and Brennan (2001) provide in-depth data related to LCA shortcomings. Other issues include setting the boundaries, allocation through proportionally distributing the responsibility for inputs used (resource consumption) and undesired outputs (emissions) of a process, the costs of data collection as LCA strongly relies on the quality of the data, etc. The most significant inadequacy that relates to this research is that LCA lacks a rigorous thermodynamic framework which is elemental for analyzing ecosystems and in certain situations it may even violate thermodynamic laws (Hau 2005).

Several attempts have been made to use Life Cycle Assessment for building evaluation; the most recent and notable being the Life Cycle-based Zero Energy Building or LC-ZEB (Hernandez and Kenny 2010). LC-ZEB is a simplified methodology to include the embodied energy of building components together with the energy used in operation. Although this research approach attempts to follow ecological modeling principles, there are shortcomings such as non-inclusion of the energy of material formation in the LCA; the selection of primary energy as an indicator, in particular, when renewable energies are considered; in addition, the approach does not quantify the use of progressive replacement of non-renewable resources by renewable resources to achieve a net energy balance.

\subsection{Emergy Analysis}

Emergy analysis is an environmental accounting procedure through which a consideration of the entire life-span of a building from formation-extraction-manufacturing to maintenance and operation cycles may be achieved. Solar and other energies that have been drawn upon for the formation-extractionmanufacturing of materials, the energy and material inflow necessary to resist degradation, and the resources required for operational use of the building constitute the available energy-emergy measure of what is required for the structure and function of a building. Energy Systems Theory and Emergy Analysis (Odum 1983; 1996) through the development of integrated environmental accounting methods can offer a holistic solution for such an analysis. In addition to providing a thermodynamic framework for analyzing energy transformations in building design and construction, emergy analysis offers several indices for comprehensive evaluation of a building system and its sub-systems.

Solar emergy is the available solar energy previously used-up, both directly and indirectly, to make a service or a product (Odum 1971; 1983; 1996). Solar energy is used as the common denominator to express all resources, services and goods in terms of their relative ability to do work in a system. Thus, any product or service uses a common unit, "solar emergy Joule" (semJ), as the unit of emergy. There are three main types of unit emergy intensity values namely, "transformity," "specific emergy," and "emergy per unit money." Transformity is the solar emergy required to make 1 unit of available energy of a quantity (e.g., a Joule of a product or service). Its units are solar emjoules per Joule (semJ/J). Specific emergy is the emergy value per unit mass of material (e.g., semJ $/ \mathrm{kg}$ ). In other words, specific emergy provides the energy that is required to concentrate materials. Emergy per unit money is used to convert monetary benefits into emergy values. The emergy of a product can be calculated by multiplying a quantity of available energy by its transformity. Available energy is energy with the capacity to do work, (i.e., it has an energy potential relative to its environment). The solar transformity of the sunlight absorbed by the earth is 1.0 by definition. Transformities are calculated based on the production process. This leads to changes in transformities of the same product made by different production processes.

In the context of Energy Systems Theory (Odum 1994), transformity measures the position of any energy flow or storage in the universal energy hierarchy (Odum 1996). Additionally, transformities are measured relative to a baseline.

The baseline is developed using the three primary energy sources to the planet, i.e., solar radiation, deep heat generated from residual heat and radioactive decay within the earth, and the gravitational attrac- 


\section{Srinivasan, Braham, Campbell, and Curcija}

tion of the sun and moon (Odum 1996; Campbell 2000). Transformities used in this paper use 9.44E+24 $\mathrm{sej} / \mathrm{yr}$ baseline from Odum (1996). Several research projects have been conducted to develop transformity values, most notably Buranakarn (1998) for building materials, who used this baseline in his work. Emergy analysis uses thermodynamic principles for environmentally conscious decision-making. In other words, emergy analysis provides a "total environmental analysis" that goes beyond typical thermodynamics and includes all environmental energies involved in the system under investigation. Based on the above, emergy analysis is chosen for this paper as a tool to evaluate environmental building design.

Only a handful of research efforts have focused on assessing buildings using emergy analysis: evaluation of recycling and reuse of building materials (Buranakarn 1998); emergy associated with the operation of a Building (Meillaud et al. 2005); building manufacturing, maintenance and use - development of Embuilding indices (Pulselli et al. 2007); energy and emergy based cost-benefit evaluation of building envelopes relative to geographical location and climate (Pulselli et al. 2009); and emergy evaluation of a green façade (Price and Tilley 2010). Although these studies focused on the use of emergy as a tool to evaluate building materials and buildings as a whole, and to develop performance indices for further exploration, there is not yet a comprehensive method to maximize the emergy of renewable resource use relative to a finite limit or potential as a way to optimize building design before any renewable or non-renewable resources are expended.

\section{RENEWABLE EMERGY BALANCE}

Building materials may be broadly classified as being derived from renewable and/or non-renewable resources. From the initial formation over its lifetime, each resource may be categorized by these two resource types. While the use of renewable resources can be beneficial for sustainability (i.e., renewable resources must be used at a rate that does not exceed their natural rate of replacement to be considered sustainable), a portion of the non-renewable resources may be exploited to further develop renewable resources (Daly, 1990; Odum and Odum 2001).

To attain the most sustainable system possible, it is crucial that as the non-renewable resources are depleted, they be replaced with renewable ones. In other words, in the renew-non-renew model, the integrated system that uses different technologies to obtain non-renewable energy to grow and power itself will be replaced progressively by renewable ones. Daly (1990) proposed a pathway wherein nonrenewable resources are substituted to generate greater use of renewable resources in line with a "quasisustainability" principle. Bastianoni et al (2009) have shown the theoretical possibilities of using nonrenewable resources to take advantage of renewable resources.

The quasi-sustainability principle can be extended to buildings to develop metrics related to renewnon-renew substitution. In other words, as emergy accounting advances for a particular system, renewability and the non-renewability of materials are appropriately identified. This requires the identification and listing of non-renewable resources that have the potential to be substituted by renewable resources. Thus, the use of non-renewable resources to improve system capacity to exploit renewable resources permanently will aid the development of a quasi-sustainable solution. Such resources that may be replaced with renewable resources possess the property "Renewable Substitutability" (Srinivasan 2011).

For buildings, the novelty of investing non-renewable resources to boost permanently renewable resource use will shift a building towards self-sustenance in renewable emergy terms or toward a "Renewable Emergy Balance" (Srinivasan 2011). Thermodynamically, an REB building preserves a balanced Renewable Substitutability through investment (or progressive improvement) of all non-renewable resources with Renewable Substitutability to utilize renewable resources. The central aspect of a Renewable Emergy Balance is the computation of an explicit quantity of renewable resources integrated over the building's lifetime, also referred to as the maximum renewable emergy potential of the building, after maximization of renewable resource use during the design phase of the building. This limit is a moving target and improves as the technology improves to integrate and/or generate more renewable resources. The significance of this limit is that it alleviates any ambiguity related to a benchmark that is required to achieve a higher level of sustainability. 


\section{Srinivasan, Braham, Campbell, and Curcija}

Figure 1 illustrates the cumulative emergy use of a typical building. The duration (in years) between phases A and B represents the emergy content of the building materials through formation, extraction and manufacturing. The duration between points $\mathrm{B}$ to $\mathrm{C}$ represents the building lifetime during which the building uses energy for its day-to-day operations and for maintenance. Phases B1 and B2 represent building component replacement times according to the maintenance schedule followed during the building's lifetime.

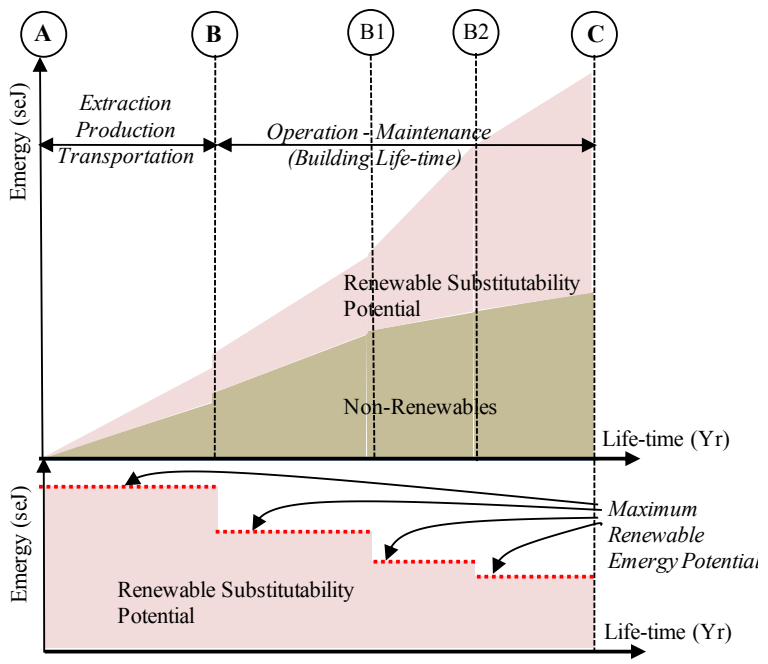

Figure 1: Energy Balance Verification framework for NZE buildings.

Using emergy analysis and through the identification of the Renewable Substitutability of all nonrenewable resources, the emergy content may be split into non-renewables with Renewable Substitutability potential and un-substitutable non-renewables, i.e., non-renewable resources that cannot be substituted with renewables using the best available technology. This identification of Renewable Substitutability is a significant component of the Renewable Emergy Balance.

At the end of building life-time, the material may end up in a landfill or reused (deconstruction). The emergy content of material that may be reused is replaced with the emergy content of overall building materials for REB computation. This process is, however, not shown in Figure 1, but explained in detailed in the following section. This notion underscores the reality that non-renewable resources without Renewable Substitutability may not be altered back to their original structure without expending available energy. Non-renewable resources may not be replenished to their native forms, unlike the renewable resources, particularly after diverse transformations that are required to make a product. In other words, non-renewable resources with Renewable Substitutability require less energy to replenish as compared to such resources without Renewable Substitutability.

Non-renewable resources with Renewable Substitutability have a potential to be replaced by renewable resources and this should be exploited to move toward the construction of more sustainable buildings. Through emergy analysis, this definite quantity (the maximum potential) needed to achieve a Renewable Emergy Balance can be calculated. Moreover, as conscious decision-making prevails over material selection (as indicated in phases B1 and B2), the Renewable Substitutability split between the potentially substitutable resources and the hard core non-renewable resources changes, thereby changing the maximum renewable emergy potential. This is evident in the lower portion of the graph showing the decrease in the maximum Renewable Substitutability potential over building's lifetime.

The maximum potential is a moving target that improves based on improvements in renewable resources technology. Thus, the Renewable Emergy Balance over the lifetime of a building is achieved by attaining the maximum renewable emergy potential. The advantage of this method is that the trend may be projected for the entire building lifetime. Based on the actual realization of the building's operation and maintenance, errors, if any, may be corrected for the remainder of the time period thus adjusting the 


\section{Srinivasan, Braham, Campbell, and Curcija}

accuracy of the maximum renewable emergy potential curve. Additionally, various alternatives may be simulated before they are implemented for the building project.

Such an approach would expand conscious decision-making and, possibly, produce a paradigm shift in the way non-renewable energy is used in the manufacturing process of building materials. Thus, by progressive improvement, over the lifetime of the building, if all non-renewable resources with Renewable Substitutability are replaced by renewable resources, the building will approach a Renewable Emergy Balance. This process fits well within the quasi-sustainability principle of "a prosperous way down" (Odum and Odum 2001).

This paper develops a method to maximize renewable resource use through emergy analysis to close the gap between current environmental building design and the over-arching goal of creating buildings that contribute to the overall sustainability of the geobiosphere. The objective of this paper is to develop a maximum limit for renewable resource substitution, assess the performance of systems and maximize renewable resource use. The paper proposes a Renewable Emergy Balance in environmental building design that maximizes renewable resource use through disinvestment in non-renewable resources that may be substituted with renewable resources. In order to the state of a system relative to its Renewable Emergy Balance, a structured assessment method is followed as discussed in the next section.

\section{RENEWABLE EMERGY BALANCE ASSESSMENT}

Renewable Emergy Balance in environmental building design maximizes renewable resource use through disinvestment of non-renewable resources and through renewable resource substitution. The building environmental system boundary includes the building structure, its components specifically those that enable conditioning the thermal environment. However, the system does not include building occupants. In addition to the building structure, the building components are comprised of the Heating, Ventilation and Air-Conditioning (HVAC) systems, electrical, lighting systems, the appliances and furniture that occupy the spaces.

The conceptual Energy Systems Diagram of a typical building is presented in Figure 2. The boundary of the system is defined by the boundaries of the property on which the building is located. The components are organized in a hierarchical order from left to right based on the energy quality (transformity)of the energy and materials used in manufacturing and maintenance of the building HVAC system, building structure, appliances, furniture, electrical systems including lighting, energy use (i.e., electricity, natural gas, etc.), material content of appliances, etc., and services.

The building structure is an important component of the system. The rectangular box represents the building envelope and its structure. Envelope structure enables heat transfer between the outdoor conditions in the environment and the building indoors. Based on the thermal conditioning requirements, heating or cooling may be necessary. Envelope structure is comprised of opaque and transparent surfaces. For opaque systems, heat is added to the interior spaces using conduction of heat through the structure. For transparent systems such as glazing, heat is added by conduction, convection and radiation. In addition to external renewable sources using the sun's radiation, any additional heating requirement is supplemented by HVAC systems. Heat is also generated by operating the electrical systems of the building. Transparent envelope systems enable heat transfer and daylight penetration. Daylighting, a renewable resource, using outdoor diffused lighting can provide a significant source of interior lighting. Additional lighting requirements may be satisfied using electrical lighting systems. The systems diagram does not illustrate the energy pathways for material reuse. 


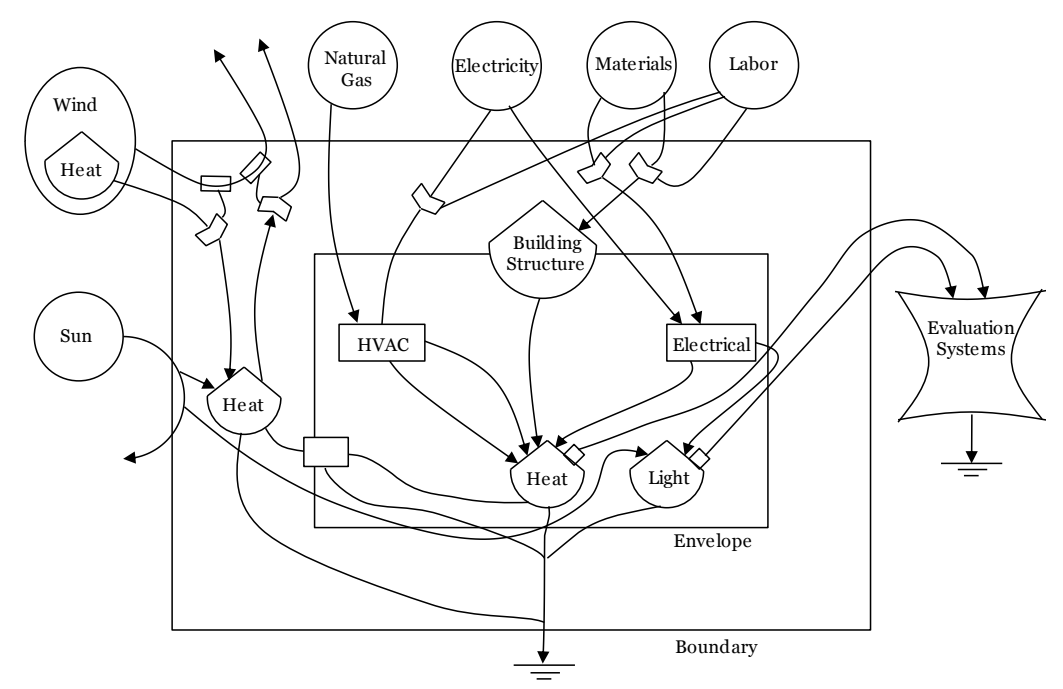

Figure 2: Systems diagram of building environmental design showing energy pathways.

Renewable Emergy Balance assessment is comprised of three components namely, the manufacturing and maintenance emergy analysis, the building operation emergy and the maximum renewable emergy potential, Figure 3. The manufacturing and maintenance emergy analysis component enables the calculation of emergy values split into renewable resources, non-renewable resources with Renewable Substitutability and non-renewable resources, per se. This is followed by the building operations emergy component. In this component, building emergy use during operation is split into the three independent emergy portions (renewable resources, and non-renewable resources with Renewable Substitutability and those that cannot be easily replaced). If the building is an existing facility, the operational energy use is obtained from historical data. If the building is a new facility and the evaluation is conducted during the design phase, a detailed energy model is developed to determine the energy used in operations.

The emergy used for operations is calculated by multiplying the transformities of different energy source (i.e., electricity, natural gas, etc.) by the corresponding usage data. Finally, the emergy content of estimated material reuse and waste is determined. Using the results obtained from the above two components, the maximum renewable emergy potential is computed.

The maximum renewable emergy potential is a moving target that changes based on improvements in renewable resource use during maintenance and other technological advancements in material manufacturing processes. Thus, by replacing nonrenewable resources with Renewable Substitutability with renewable resources over the building's life-time, a state of Renewable Emergy Balance is approached.

\subsection{Manufacturing and Maintenance Emergy Analysis}

For every building component, the formation-extraction-manufacturing emergy quantity is assessed.

Step 1: Emergy analysis in "Formation-Extraction-Manufacturing." For each building component emergy data for formation-extraction-manufacturing is calculated. The emergy values are split into three portions namely renewable resources, nonrenewable resources with Renewable Substitutability and nonrenewable resources, per se. These values are located in a building materials emergy database. This database encompasses the most recent emergy data available for building materials. Odum (1996) and several other researchers have published material transformities. Such transformities are fundamental to this assessment. Therefore, the crucial task involves identifying and organizing all available emergy data for building materials with suitable references for easy access. The database corresponds to the formationextraction-manufacture phase. 


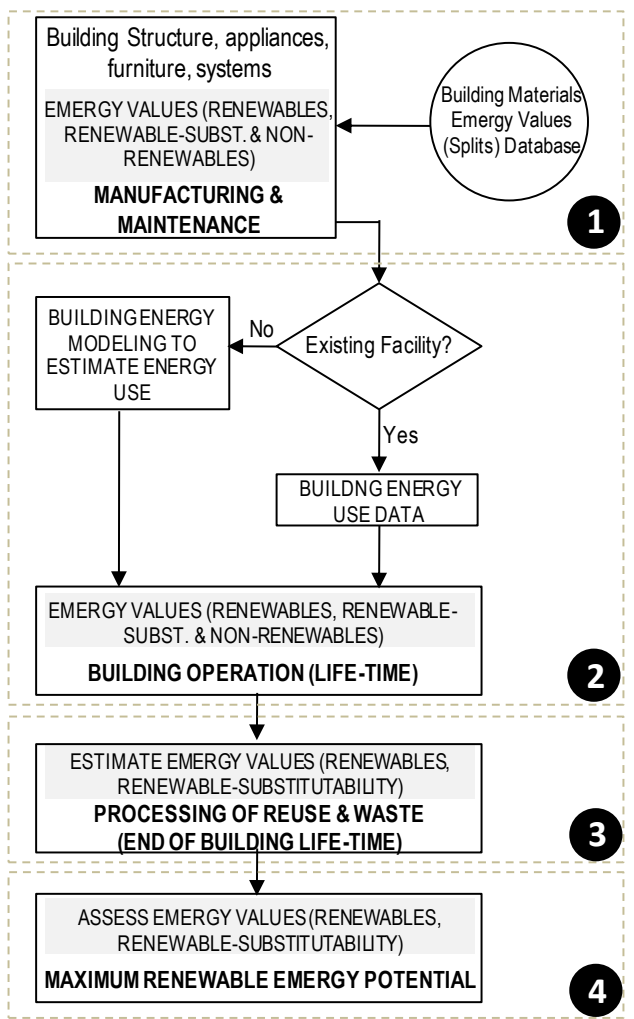

Figure 3. Renewable Emergy Balance assessment structure.

As a building is studied in detail, the building material information is listed. These building materials are then matched to the transformities data to derive the emergy content. However, the existing literature often does not include information related to renewable resources used and the Renewable Substitutability of the inputs to the production of structural materials. Using the earlier example, portions of electricity and water drawn for cement production, in addition to the oil used might be replaced with renewable resources. This quantity is tracked for all building materials. Thus, to measure the Renewable Substitutability of concrete, the individual Renewable Substitutability of the raw materials used in concrete manufacture, such as cement, sand and water are used. Thus, the manufacturing emergy quantity of all building components is represented as,

$$
\sum_{i=1}^{x} R_{\text {manufactuing }}=\sum_{i=1}^{x}\left(R_{m i}+R S_{m i}+N R_{m i}\right)
$$

where $R_{m}, R S_{m}$ and $N R_{m}$, respectively, represent the renewable, nonrenewable with Renewable Substitutability and non-renewable emergy of the building materials used in cement manufacture. The total emergy content is computed by evaluating every building component (represented as $x$ ).

Step 2: Emergy analysis in "Maintenance." Maintenance restores the depreciation of energy associated with building components. For example, building fenestration (glazing) is replaced for maintenance. The building component replacement schedule is used to determine the emergy associated with replacement components. Since new components replace old, worn out components, it is crucial to count only the difference in emergy values as opposed to adding the new replacement emergy values to the existing structure. It is important to select the replacement component based on its environmental performance and its renewable resource content.

The emergy values are split into three portions as discussed in earlier step. Thus, the maintenance emergy quantity of all building components during its life-time is represented as, 


\section{Srinivasan, Braham, Campbell, and Curcija}

$$
\sum_{i=1}^{y} R_{\text {maintenance }}=\sum_{i=1}^{y}\left(R_{n i}+R S_{n i}+N R_{n i}\right)
$$

where $R_{n}, R S_{n}$ and $N R_{n}$, respectively, represent the renewable, nonrenewable with Renewable Substitutability and non-renewable emergy of building materials used for maintenance. The total emergy value is computed by including the difference in emergy values due to replacement of building components and this is conducted based on the maintenance schedule (represented as $y=$ time of replacement).

\subsection{Energy Used in Building Operations}

If the building is an existing facility, the emergy used for operations is obtained from historical data. If the building is a new facility and the evaluation is conducted during the design phase, a detailed energy model is developed to determine energy use in this category.

Step 3: Energy used for operations. The energy used for operations is calculated by multiplying the transformities of different energy sources (i.e., electricity, natural gas, etc.) by the corresponding usage data. Similar to STEP 1, the emergy values are split based on their renewable, Renewable Substitutability and non-renewable content. Thus, the quantity of emergy from all energy sources used during operation of the building during its life-time is represented as,

$$
\sum_{i=1}^{z} R_{\text {operation }}=\sum_{i=1}^{z}\left(R_{p i}+R S_{p i}+N R_{p i}\right)
$$

where $R_{p}, R S_{p}$ and $N R_{p}$, respectively, represent the renewable, nonrenewable with Renewable Substitutability and non-renewable emergy values of energy sources supporting building operations. The total emergy used for operations is computed by adding the emergy used for this purpose over the building's life-time (represented as $z=$ building life-time in years).

\subsection{Energy Use in Material Reuse and Waste at the end of Building Life-time.}

Material reuse is crucial for replacement of virgin building materials. Using energy systems theory, the importance of material reuse may be proved as discussed below.

Step 4: Energy used for processing material reuse and waste. The energy used for processing material reuse and waste at the end of building life-time is estimated. Similar to building material "formationextraction-manufacturing," all related emergy values, split based on their renewable, Renewable Substitutability and non-renewable content, is estimated. Material reuse is represented as,

$$
\sum_{i=1}^{v} R_{\text {reuse }}=\sum_{i=1}^{v}\left(R_{r i}+R S_{r i}+N R_{r i}\right)
$$

where $R_{r}, R S_{r}$ and $N R_{r}$, respectively, represent the renewable, nonrenewable with Renewable Substitutability and non-renewable emergy of building materials that can be reused. The total emergy value is computed by including the difference in emergy values due to replacement of building components and this is conducted based on the maintenance schedule (represented as $v=$ reuse materials and waste).

\subsection{Maximum Renewable Emergy Potential}

To maximize renewable resource use over the life cycle of a building, the maximum renewable emergy potential for the building is calculated.

Step 5: Maximum renewable emergy potential. The maximum renewable emergy potential of the building is found by adding all the Renewable Substitutability potentials during manufacturing, maintenance and operation of the building. Thus, it can be represented as,

$$
\left\{\sum_{i=1}^{x} R S_{m i}+\sum_{i=1}^{y} R S_{n i}+\sum_{i=1}^{z} R S_{p i}+\sum_{i=1}^{v} R S_{r i}\right\}
$$




\section{Srinivasan, Braham, Campbell, and Curcija}

This emergy value when divided by the building life-time provides the average annual maximum renewable emergy potential. Decision-making during design (selecting building materials during manufacturing), maintenance and energy use for operations during the building's life-time should aim at maximizing the quantity of renewable resources used. The total renewable resource use is represented as,

$$
\left\{\sum_{i=1}^{x} R_{m i}+\sum_{i=1}^{y} R_{n i}+\sum_{i=1}^{z} R_{p i}+\sum_{i=1}^{v} R_{r i}\right\}
$$

In order to achieve a Renewable Emergy Balance, the renewable resource use should approach or be equal to the Renewable Substitutability of the building. This is represented below,

$$
\left\{\sum_{i=1}^{x} R_{m i}+\sum_{i=1}^{y} R_{n i}+\sum_{i=1}^{z} R_{p i}+\sum_{i=1}^{v} R_{r i}\right\} \rightarrow\left\{\sum_{i=1}^{x} R S_{m i}+\sum_{i=1}^{y} R S_{n i}+\sum_{i=1}^{z} R S_{p i}+\sum_{i=1}^{v} R S_{r i}\right\}
$$

There are two scenarios related to reuse of building materials at the end of building life-time:

(a) If material reuse is pursued at end of building life-time, the emergy content of reuse material must be subtracted from the total emergy content of building materials during "FormationExtraction-Manufacturing." Essentially, reuse of building materials at the end of building lifetime is a strong incentive toward energy balance backed by energy systems theory.

(b) If material reuse is not pursued at end of building life-time, it is a disadvantage to the building, and is not recommended. In this scenario, energy use in material reuse and waste at the end of building life-time is not included. Similarly, the replacement of emergy content of reuse materials is also not included.

During building design (if the building is a new facility), conscious decision-making oriented toward improving renewable resource use is important. Similarly, during replacement of building components following the maintenance schedule, it is important to identify materials that possess greater renewable resource content in addition to materials with superior environmental performance. Additionally, by virtue of reducing energy use in operations over the building's life-time, the Renewable Substitutability associated with this phase of the building's life cycle can be significantly reduced. This involves appropriate selection of energy sources that maximize the overall renewable resource use to approach a Renewable Emergy Balance.

\section{CONCLUSIONS}

The following lists the major contributions that this paper made to the environmental accounting of buildings.

- Development of a method to assess the renewable emergy balance of a building. Renewable emergy balance buildings promote a high standard of sustainability by optimizing the use of renewable energy and materials over the entire life-cycle of the building from formation-extractionmanufacturing to maintenance and operation, and reuse at the end of building life-time.

- Maximize renewable resource use through progressive disinvestment of all non-renewable resources that may be substituted with renewable resources, thereby contributing to the overall sustainability of the geobiosphere.

- Development of methods to determine the maximum renewable emergy potential for buildings.

- Alleviate any ambiguity related to the limit or benchmark that is set to achieve higher levels of sustainability.

If this approach was adopted to guide building construction, it would expand conscious decision-making to make buildings more sustainable and, possibly, lead to a paradigm shift in the way non-renewable resources are used in the manufacturing of building materials, which is currently of interest, but remains unchecked. 
Srinivasan, Braham, Campbell, and Curcija

\section{REFERENCES}

Bastianoni, S., R. Pulselli and F. Pulselli. 2009. "Models of Withdrawing Renewable and Non-renewable resources based on Odum's energy systems theory and Daly's Quasi-Sustainability Principle." Ecological Modelling 220: 1926-1930.

Buranakarn, V. 1998. "Evaluation of Recycle and Reuse of Building Materials Using the Emergy Analysis Method." PhD Dissertation, University of Florida, FL.

Burgess, A. and D. Brennan. 2001. "Application of Life Cycle Assessment to Chemical Processes." Chemical Engineering Science, 56: 2589-2604.

Campbell, D. 2000. "A Revised Solar Transformity for Tidal Energy Received by the Earth and Dissipated Globally: Implications for Emergy Analysis." In Emergy Synthesis: Theory and Applications of the Emergy Methodology. Proceedings of the First Biennial Emergy Analysis Research Conference, edited by M. Brown, S. Brandt-Williams, D. Tilley and S. Ulgiati, 255-264. Center for Environmental Policy, Dept of Environmental Engineering Sciences, University of Florida, Gainesville, FL.

Crawley, D., S. Pless and P. Torcellini. 2009. "Getting to Net Zero." Journal Article NREL/JA=55046382.

Daly, H. 1990. "Toward some Operational Principles of Sustainable Development." Ecological Economics 2: $1-6$.

DOE. 2010. Renewable generation data, Energy Information Administration of US Department of Energy. Accessed December 12, 2010 http://www.eia.doe.gov/cneaf/electricity/epa/epa_sum.html

Guinee, J., R. Heijungs, H. Udo de Haes and G. Huppes. 1993. "Quantitative Life Cycle Assessment of Products 2: Classification, Valuation and Improvement Analysis." Journal of Cleaner Production 1: 81-91.

Guinee, J., H. Udo de Haes and G. Huppes. 1993. "Quantitative Life Cycle Assessment of Products 1: Goal Definition and Inventory." Journal of Cleaner Production 1: 3-13.

Hau, J. 2005. "Toward Environmentally Conscious Process Systems Engineering via Joint Thermodynamic Accounting of Industrial and Ecological Systems." PhD dissertation, The Ohio State Univ.

Herendeen, R. 2004. "Energy Analysis and Emergy Analysis - A Comparison." Ecological Modeling, $178(1-2): 227-237$.

Hernandez, P., and P. Kenny. 2010. "From Net Energy to Zero Energy Buildings: Defining Life Cycle Zero Energy Buildings (LC-ZEB)." Energy and Buildings 42: 815-821.

Holling, C. 1986. "The resilience of terrestrial ecosystems: local surprise and global change." In Sustainable Development in the Biosphere., edited by W. Clark and R. Munn, Oxford Univ. Press, pp. 292320.

Meillaud F., J. Gay and M. Brown. 2005. "Evaluation of a Building Using the Emergy Method." Solar Energy 79: 204-212.

Odum, H. 1971. Environment, Power and Society. Wiley, New York.

Odum, H. 1983. Systems Ecology. Wiley, New York.

Odum, H. 1994. Ecological and General Systems. University Press of Colorado, Niwot, CO (reprint of Systems Ecology, John Wiley, 1983).

Odum, H. 1996. Environmental Accounting: Emergy and Environmental Decision Making. Chichester Wiley, New York, NJ.

Odum, H., 1999. "Limits of information and biodiversity," in: Löffler, H. and E. Streissler. Sozialpolitik und Ökologieprobleme der Zukunft. Verlag der Österreichischen Akademie der Wissenschaften, Wien, pp. 229-269.

Odum, H. and E. Odum. 2001. A Prosperous Way Down. Principles and Policies. University Press of Colorado, Boulder, CO, USA.

Price, J. and D. Tilley. 2010. "Emergy Evaluation of Green Façade," Proceedings of the Sixth Biennial Emergy Research Conference held in Gainesville FL, Jan 14-16. 
Pulselli, R., F. Simoncini, S. Pulselli and S. Bastianoni. 2007. "Emergy Analysis of Building Manufacturing, Maintenance and Use: Em-building Indices to Evaluate Housing Sustainability." Energy and Buildings 39: 620-628.

Pulselli, R., E. Simoncini, R. Ridolfi, S. Bastianoni. 2008. "Specific emergy of cement and concrete: An energy-based appraisal of building materials and their transport." Ecological Indicators, 8(5): 647656.

Pulselli R., M. Simoncini and N. Marchettini. 2009. "Energy and Emergy based Cost-Benefit Evaluation of Building Envelopes Relative to Geographical Location and Climate." Building and Environment 44: $920-928$.

Srinivasan, R. 2011. "Re(de)fining Net Zero Energy: Maximizing Renewable Resource Use through Emergy Analysis of Environmental Building Design." Unpublished PhD dissertation, University of Pennsylvania, Philadelphia PA.

Toricellini, P., S. Pless, M. Deru, and D. Crawley. 2006. "Zero Energy Buildings: A Critical Look at the Definition.” ACEEE Summer Paper on Energy Efficiency in Buildings. Golden, CO: NREL.

\section{AUTHOR BIOGRAPHIES}

RAVI SRINIVASAN is Assistant Professor of Low / Net Zero Energy buildings at the M.E. Rinker, Sr. School of Building Construction, University of Florida. He is one of the few energy simulation experts at the top of the highly specialized field of building science. Prior to joining University of Florida, he was working as the Director of Technology and Innovation at the Green Roundtable. Dr. Srinivasan has consulted on Low/Net Zero Energy buildings including the first NZE housing for the Boston Housing Authority and projects with prominent firms such as WSP Flack \& Kurtz. He has conducted several NZE and energy modeling trainings for AEC firms. The NZE training program he developed was awarded 2010's "Most Innovative Product" by Massachusetts USGBC chapter. Dr. Srinivasan has also had significant experience evaluating the energy modeling work of other experts and professionals in the field of building science. Dr. Srinivasan holds M.S. in Engineering from the University of Florida, M.S and Ph.D. in Architecture from the University of Pennsylvania. His contact email address is sravi@ufl.edu

WILLIAM BRAHAM is a Professor of Architecture at the University of Pennsylvania, where he is Director of the Master of Environmental Building Design program at the Department of Architecture. At Penn, Dr. Braham teaches graduate courses on ecology, technology, and design. In 2006 he published a book called Rethinking Technology: A Reader in Architectural Theory, and In 2002 published a book called Modern Color/Modern Architecture: Amédée Ozenfant and the genealogy of color in modern architecture (www.modcolor.com). Dr. Braham received an engineering degree from Princeton University and an M. Arch and Ph.D. Arch. From the University of Pennsylvania, where he has taught since 1988. His email address is brahamw@pobox.upenn.edu

DANIEL CAMPBELL is a Research Ecologist at the US EPA's Office of Research and Development, Atlantic Ecology Division. Dr. Campbell is one of the very few emergy experts. Most recently, he updated the baseline transformity used in emergy analysis and also performed studies of US states using emergy analysis. Dr. Campbell has published extensively in scientific journals and conference proceedings. He was a student of Dr. Howard T. Odum who developed emergy synthesis at the University of Florida. Dr. Campbell holds Ph.D. from the University of Florida. His email address is Campbell.Dan@epamail.epa.gov

CHARLIE CURCIJA is a Senior Research Scientist in Building Technologies Division in Lawrence Berkeley National Laboratory (LBNL). Prior to joining LBNL, Dr. Curcija was the president of DesignBuilder Software USA, consulting company in Millers Falls, Massachusetts, dedicated to the development of models and software tools for building energy assessment. He has been actively involved with 


\section{Srinivasan, Braham, Campbell, and Curcija}

ISO and NFRC standard development and has provided major contribution to the fenestration standards in simulation and testing. His email address is dccurcija@1bl.gov 